Just Shut The Bloody Place Down Masterplan from Region for some weeks: Take heart! Medical audit and cost-effectiveness studies may lack the raw excitement of a hospital closure, but, believe me, the opportunities they create for the alert Health Service Manager are limitless. Confidentially, I can tell you that we are already in sight of our 1992 target of one manager per bed, so those undignified scrambles at siesta time will soon be a thing of the past.

Colleagues, let us march sincerely forward into a new era, when managerial knowhow and administrative skill will finally banish chronic illness and suffering from the presciently named Health Service.

\title{
Caption Competition
}

Readers are invited to use their skill and judgement to provide appropriate dialogue for the picture below. Three prizes of books from the Gaskell Press will be awarded to the winners.

Completed entries should be forwarded to Elaine Millen at the Psychiatric Bulletin by the end of June.

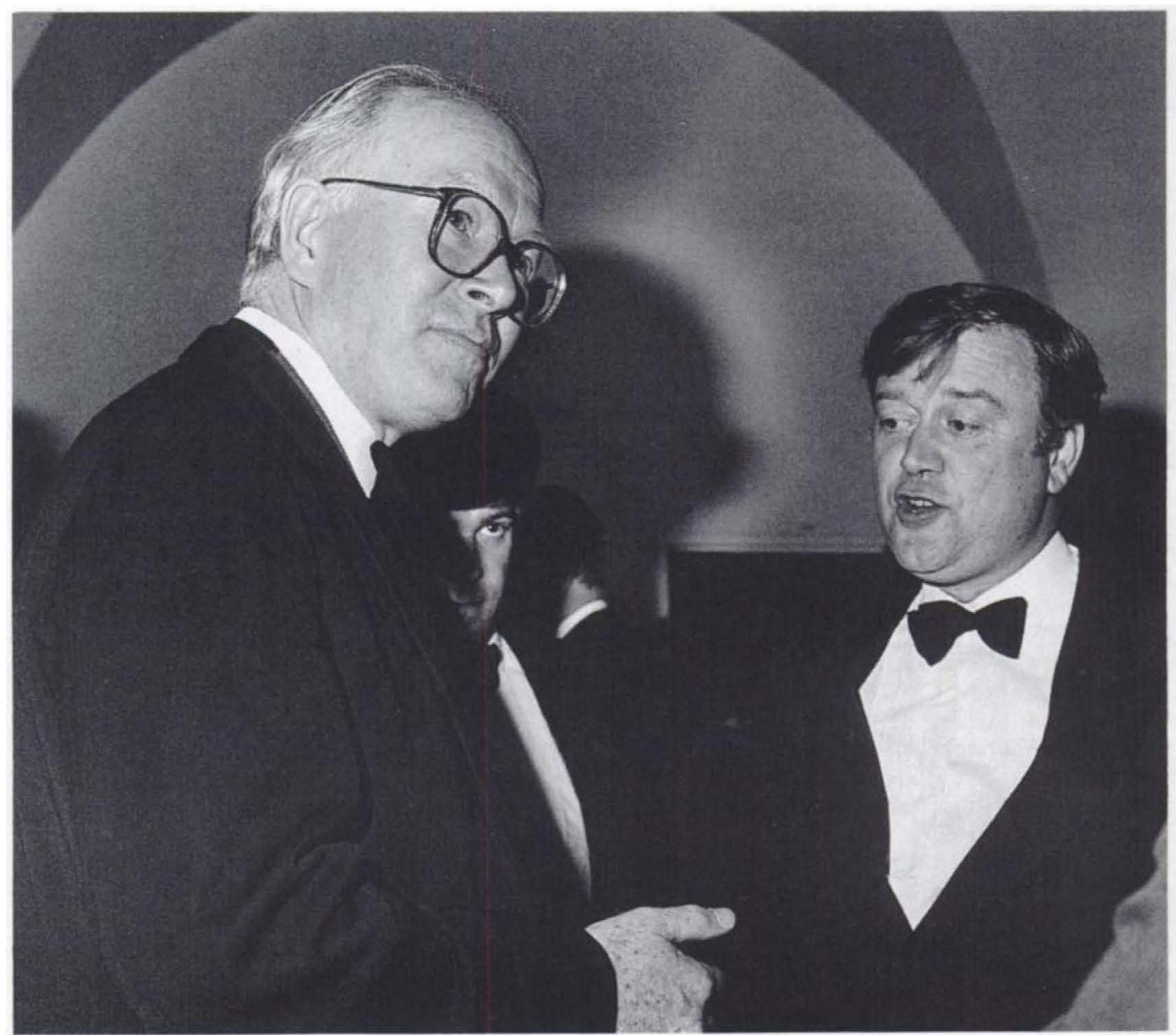

Dr Jim Birley, President, Royal College of Psychiatrists, in conversation with Mr Kenneth Clark, Health Secretary. 